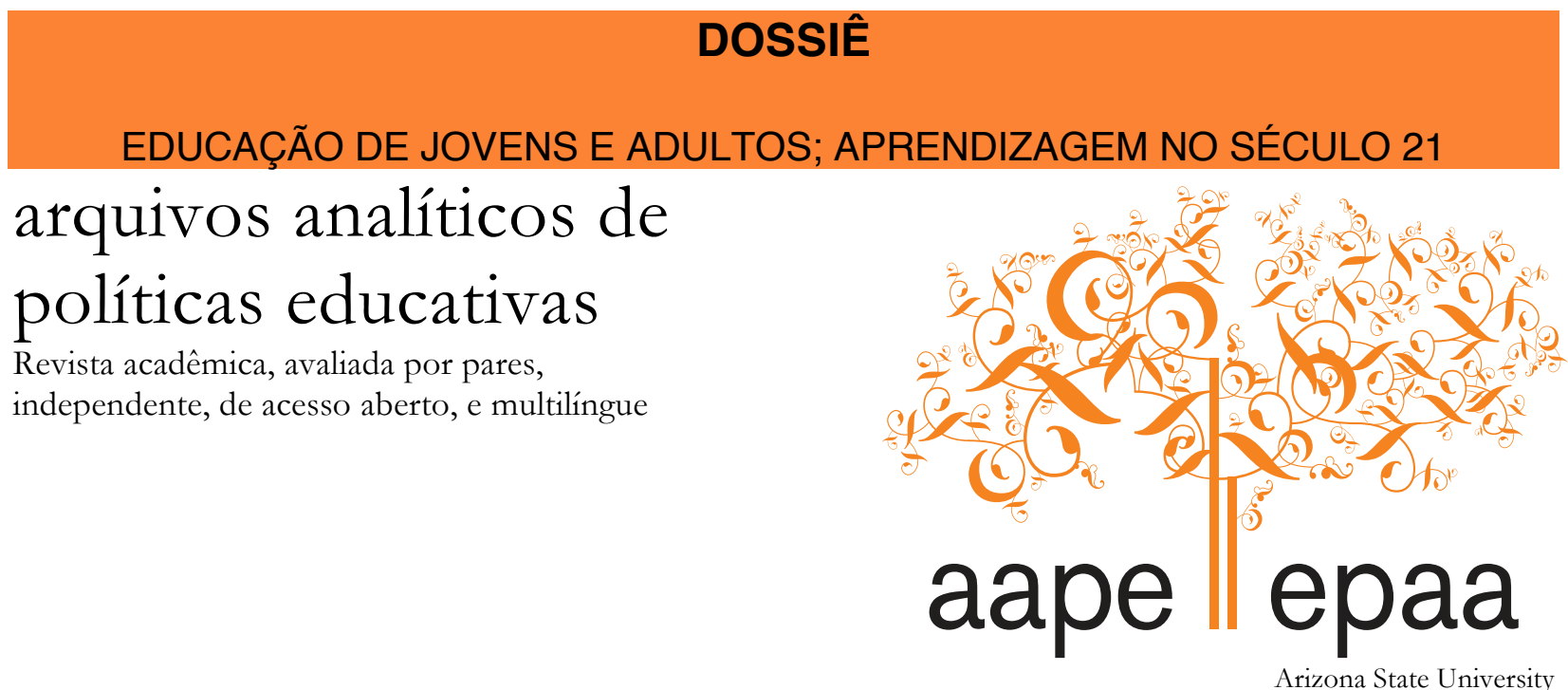

Arizona State University

\title{
Pesquisa Colaborativa: a (per) feição de uma nova pesquisa na Educação de Jovens e Adultos e a implicação dos sujeitos
}

\author{
Marinaide Lima de Queiroz Freitas \\ Nadja Naira Aguiar Ribeiro \\ Universidade Federal de Alagoas - UFAL \\ Brasil
}

Citação: Freitas, M. L. Q. E Ribeiro, N.N.A. (2014). Pesquisa Colaborativa: a (per) feição de uma nova pesquisa na Educação de Jovens e Adultos e a implicação dos sujeitos. Arquivos Analíticos de Políticas Educativas, 22 (64). http://dx.doi.org/10.14507/epaa.v22n64.2014. Dossiê Educação de Jovens e Adultos. Editoras convidadas: Sandra Regina Sales \& Jane Paiva

Resumo: Este artigo, recorte de uma pesquisa longitudinal em andamento (2012-2015), tem por objetivo refletir sobre os procedimentos da pesquisa colaborativa que, ao favorecer espaços de aprendizagens entre escola e universidade, põe em relevo os movimentos de alteridade entre os sujeitos envolvidos na atividade investigativa. Empenhadas na ideia de realizar uma pesquisa com os docentes de Educação de Jovens e Adultos (EJA) da rede pública de ensino e não sobre eles, elegeuse esse tipo de abordagem para colocar em foco o ensino da leitura. Como apoio teórico e metodológico a determinadas categorias que compõem a discussão deste artigo, buscou-se interlocução com Bakhtin (2003), Freire (2006, 1981, 1979), Ibiapina (2008) entre outros que contribuem com o tema em tela. As sessões de reflexão realizadas, a exemplo do episódio analisado neste trabalho, têm revelado que os fundamentos epistemológicos e encaminhamentos metodológicos da pesquisa colaborativa, além de subverterem o modelo positivista de ciência, vêm contribuindo com a formação continuada desses professores de EJA, com o contexto escolar, bem como com os próprios pesquisadores da universidade. 
Palavras-chave: Pesquisa Colaborativa; Educação de Jovens e Adultos; Sessão de reflexão.

\section{Collaborative Research: The face of Youth and Adult Education research and the subjects implications}

Abstract: This paper, part of an ongoing longitudinal research (2012-2015), aims to reflect on the procedures of collaborative research that, by favoring spaces of learning between school and university, highlights the movements of otherness among subjects involved in research activity. Committed to the idea of making a survey of teachers of Youth and Adult Education (YAE) in the public school and not about them, this approach was elected to put focus on the teaching of reading. As theoretical and methodological support to certain categories of the discussion of this article, we sought to dialogue with Bakhtin (2003), Freire (2006, 1981, 1979), Ibiapina (2008) among others that contribute to the theme in question. The discussion sessions held, such as the episode analyzed in this work, reveals that the epistemological and methodological foundations of collaborative research, in addition to subverting the positivist model of science, contributes to the continuous education of these YAE teachers, with the school context, as well with the researchers themselves.

Keywords: Collaborative research; Youth and Adult Education; reflection.

\section{Investigación Colaborativa: el perfeccionamiento de una nueva investigación en la Educación de Jóvenes y Adultos con la implicación de los sujetos.}

Resumen: Este artículo, extracto de una investigación longitudinal en proceso (2012-2015), tiene como objetivo reflejar los procedimientos de la investigación colaborativa que, para favorecer espacios de aprendizaje entre la escuela y la universidad, pone en relieve los movimientos de alteridad entre los sujetos envueltos en una actividad investigadora. Empeñadas en la idea de realizar un estudio con los docentes de Educación de Jóvenes y Adultos (EJA) de la red pública de enseñanza y no sobre ellos, se eligió este tipo de abordaje para poner en foco la enseñanza de la lectura. Como apoyo teórico y metodológico a las determinadas categorías que componen la discusión de este artículo, se ha buscado la interlocución entre Bakhtin (2003), Freire (2006, 1981, 1979), Ibiapina (2008) entre otros que contribuyen con el tema en cuestión. Las sesiones de reflexión realizadas, por ejemplo el episodio analizado en este trabajo, han rebelado que los fundamentos epistemológicos y encaminamientos metodológicos de la investigación colaborativa, más allá de revertir el modelo positivista de la ciencia, está contribuyendo con la formación continuada de los profesores de EJA, en el contexto escolar, así como a los propios investigadores de la universidad. Palabras clave: Investigación Colaborativa; Educación de Jóvenes y Adultos; Sesión de reflexión

\section{Introdução}

Este artigo repousa sobre duas questões, em jogo no título, que a propósito reclamam a mesma ideia: é na pesquisa e pela pesquisa que muitas respostas e perguntas, intrigando os sujeitos, dissolvem o ideal de perfeição. De modo particular, foi na/pela pesquisa colaborativa, das vivências por ela exigidas, que se pode repensar o lugar da verdade e provocar um movimento outro no contexto pedagógico da Educação de Jovens e Adultos, que implicou a revelação de novos sujeitos nessa investigação.

\section{Primeiros olhares: nós e laços na relação entre escola e universidade}

No campo da Educação, muitas têm sido as histórias de parceria entre escola e universidade Histórias muitas vezes bem-sucedidas, mas outras nem sempre com final feliz. Essa parceria, 
atravessada por conflitos, também se faz, sobretudo, na/pela pesquisa. A pesquisa costuma ser o ponto de encontro (e/ou desencontros) entre escola e universidade.

Em geral, a decisão de realizar a pesquisa vem da academia. Isso coloca, não sem revés, a universidade num lugar de "domínio". Predicados do tipo: discernimento crítico, capacidade intelectual, sensibilidade, competência teórica costumam ser atribuídos ao pesquisador, dando a ideia de que a pesquisa é um privilégio para poucos - uma prerrogativa para aqueles que podem ser considerados donos da razão. E essa falsa ideia é reforçada geralmente pelo próprio investigador que muitas vezes adota uma postura indevida.

O mal-estar que ronda a relação universidade e escola, sobretudo quando se trata de pesquisa, não parece deslocado de motivo(s). Embora de forma não deliberada, é o pesquisador que chega para ditar as regras do jogo. A "propriedade" do dizer, nesse caso, é do investigador que se enuncia embasado pelo conhecimento científico. Por isso, coincidentemente ou não, antes mesmo de entrar na escola, ele já traz um problema.

Desse modo, a sensação de espaço invadido, que habita os atores sociais da escola, é de alguma forma um sentimento legítimo; e a recusa, muitas vezes, em estabelecer uma relação mais próxima dos pesquisadores não deixa de ser uma tática para evitar o olhar do outro. Esse outro que vem de outro lugar, e é preciso suportá-lo. Um estranho (em tese, alheio ao que ali se passa), imbuído do seu papel de pesquisador, que se apodera de algo que "não lhe pertence". Mas nessa recusa, afetada pelos desconfortos, a escola também revela seus excessos, quando parece querer o domínio de um território para chamar de seu. Uma atitude também impregnada de um certo empoderamento.

Há, de alguma forma, uma cena de disputa que não deixa de instalar universidade e escola numa espécie de arena. Por um lado, a fala do pesquisador carregada de um texto injuntivo na certeza de "tudo saber"; e, por outro, a atitude de resistência de gestores e professores - querendo revelar o saber que lhes completa - nada precisando aprender.

Neste imbricado de nós, é o não saber que, na verdade, precipita o desamparo dos sujeitos e coloca em descontinuidade as certezas. É o próprio cotidiano escolar, marcado de imprevisibilidades, que expõe a impossibilidade de se reduzir a realidade a fragmentos e saberes completos. Como diz Freire (2006), o espaço pedagógico se apresenta como um texto que deve ser permanentemente "lido", "escrito" e "reescrito". Ou seja, é pela via da compreensão ao que se passa na trama dessas relações escolares e pedagógicas que se pode colocar em xeque um determinado formato de pesquisa - transgredindo uma determinada ética científica que tenta aprisionar conceitos e impor o discurso da verdade.

Em que pese o mal-estar que ronda a relação universidade e escola, é pela pesquisa, constituída pelo seu caráter científico, a possibilidade de se estabelecer relações significativas entre diferentes saberes. A atividade investigativa não é uma caça à verdade, especialmente no campo da Educação. É nesse sentido que não cabe, especialmente numa pesquisa que se propõe a fazer parte da dinâmica da escola, um modelo positivista de ciência ${ }^{1}$. Afinal, tal modelo, pelos seus padrões

${ }^{1} \mathrm{O}$ modelo positivista de ciência tem como expoente August Comte (1798 -1857), cujas ideias e premissas filosóficas são baseadas nos pressupostos das ciências naturais. Segundo Comte, o conhecimento científico deve se basear na observação dos fatos, pois somente é considerado científico o que pudesse ser provado por meio de experiências. Para esse filósofo, todas as ciências deveriam se utilizar de um método único, o positivo. Portanto, o cientista deve utilizar os mesmos procedimentos metodológicos das ciências naturais, a saber: o rigor metodológico, a experiência, a neutralidade científica - baseada na ordenação e na objetividade, e a precisão dos dados. Essa é a condição sine qua non para a produção do um conhecimento, de acordo com o modelo positivista. Esse modelo, caracterizado por uma concepção de mundo determinista, pautado em crenças cartesianas, prevaleceu como formato de fazer ciência no mundo ocidental. Entretanto, segundo 
deterministas, prega a neutralidade científica. Entretanto, mais do que se preocupar com a neutralidade, é preciso compreender, nessa trama que tece os fios do cotidiano escolar, que as "palavras alheias" são reelaboradas dialogicamente em "palavras próprias alheias" (Bakhtin, 2003, p. 348), afetando, num processo criativo, tanto os pesquisadores como os sujeitos pesquisados. Ou seja,

A vida é dialógica por natureza. Viver significa participar do diálogo: interrogar, ouvir, responder, concordar. Nesse diálogo o homem participa inteiro e com toda a vida: com os olhos, os lábios, as mãos, a alma, o espírito, todo o corpo, os atos. Aplica-se totalmente na palavra, e essa palavra entra no tecido dialógico da vida humana, no simpósio universal.

(Bakhtin, 2003, p. 348)

E isso certamente vai de encontro a uma ciência que se pretende atemporal e com total controle sobre a realidade. A ciência positivista apresenta-se sob o estatuto de ser a dona da verdade. Daí que a neutralidade, a objetividade e a racionalidade são os atributos que lhe dão a ilusão deste domínio absoluto do saber. De acordo com o modelo positivista, são essas as qualidades que credenciam uma pesquisa científica. Ir de encontro a tal abordagem, porém, não é abrir mão do rigor que fazem parte do discurso científico. Entretanto o rigor, exigente para qualquer tipo de atividade científica, nada tem a ver com a neutralidade. Mas, sim, com o compromisso ético com os sujeitos implicados com a/na pesquisa.

E estar na escola - ainda que na posição de pesquisadores - é colocar-se neste entrelaçamento de nó(s), é criar laços com todos aqueles implicados com o cotidiano da escola, a saber: alunos, professores, gestores, funcionários, comunidade. É, portanto, estar submetidos à trama. Uma trama, forjada de (desa)fios das mais variadas matizes, que pode provocar um tecido de tons inesperados. No lugar de uma lógica fragmentadora, busca-se, do ponto de vista metodológico, uma compreensão integradora, reconhecendo que é do lugar do imprevisível - dos vestígios deixados pelo/no cotidiano, a possibilidade do novo. Por isso, os pesquisadores da universidade, cujas pesquisas estão voltadas para o cotidiano escolar, não trazem para este espaço "os passos de uma metodologia de pesquisa, mas a abertura para [ir] costurando a pesquisa de acordo com o que a realidade leva a fazer" (Garcia, 2003, p.206).

Portanto, uma concepção de ciência, alicerçada numa perspectiva emancipatória, deve assumir uma outra posição - tal como expressa Santos (1987, p. 28)

Em vez da eternidade, a história; em vez do determinismo, a imprevisibilidade; em vez do mecanicismo, a interpenetração, a espontaneidade e a auto-organização; em vez da reversibilidade, a irreversibilidade e a evolução; em vez da ordem, a desordem; em vez da necessidade, a criatividade e o acidente.

Daí que a urgência epistemológica é de outra ordem: desobrigar-se de um ideal de perfeição, e lançar-se ao risco de uma nova história que exige mais perguntas do que respostas. Perguntas que, certamente, nos põem em movimentos de virada. Afinal, a pesquisa, assim entendida, pode ser um lugar de provocar ações.

Japiassu (1981), é possível perceber que a realidade sobre a qual se produz os conhecimentos objetivos, está imersa em um universo sócio-político-cultural - impossível de ser olhado com neutralidade. Nesse sentido, a produção científica é marcada pela cultura na qual se insere, refletindo, sobretudo, suas contradições.

Portanto, a ciência é um conjunto de hipóteses - que podem ser refutáveis - sobre a realidade. Fazem parte da ciência não só os aspectos lógicos, da ordem natural, mas também os psicológicos e sociais (Bordin, 1985, p. 86). 


\section{Instâncias de reconhecimento: provocações entre o familiar e o estranho}

Mais do que na escrita, a escuta da palavra provoca(a)ções, pelo efeito de sentidos, pode indiciar uma relação tensa entre universidade e escola. Uma tensão geralmente marcada por estranhamentos. Tanto a comunidade escolar, como a comunidade acadêmica parecem não se reconhecer como parceiras. Os sujeitos da escola, especialmente nos últimos tempos, têm se mostrado arredios às investidas de se tornarem um mero objeto de pesquisa. Eles certamente compreendem, do ponto de vista ético da ciência, que "a prática cotidiana restaura com paciência e tenacidade um espaço de jogo, um intervalo de liberdade, uma resistência à imposição (de um modelo, de um sistema, de uma ordem) - para defender a autonomia de algo próprio" (Certeau e Giard, 1996, p. 341-342). Por isso, não raro, tentam taticamente driblar o assédio. Já os pesquisadores, por sua vez, parecem ressentidos por não encontrarem escancaradas as portas da escola para as "suas" pesquisas. É um jogo de relações mal-sucedidas e, por isso mesmo, impregnada de vida - de experiência estética. Em última análise, é justamente a alteridade provocada entre o familiar e o estranho, que produz a emergência do novo. O estranhar é um modo de (se) estar com o outro, de negociar com o outro, de (se) expor ao outro, de ver-se-vendo. E o que disso retorna é o que põe em relevo o processo emancipatório - o efeito do ato formativo.

\section{Outra leitura: a feição da pesquisa em contextos escolares de EJA}

A injunção do tipo "nós sabemos ensinar a ensinar" é quase sempre uma prerrogativa da qual se vale o pesquisador da Educação, já que a universidade é o lócus da produção do conhecimento. Ainda que não expresse explicitamente essa fala, os pesquisadores parecem, em sua maioria, possuir uma vara de condão para resolver os problemas do cotidiano escolar, bem como dos professores e dos alunos ${ }^{2}$.

Diante do apelo de pesquisadores para ter a escola como campo de pesquisa, resta muitas vezes às instituições de ensino aceder à presença de corpos estranhos à sua rotina. Nesse sentido, muitas pistas nos são dadas por meio de palavras, gestos, expressões fisionômicas, e até mesmo incompatibilidades de horários, para demonstrar insatisfações e contrariedades. $\mathrm{Na}$ verdade, mais parecem táticas de sobrevivência e de proteção à desestabilidade que o outro (de fora) pode provocar. Como diz Certeau (1994, p.19) "A tática realiza-se em momentos propícios, quanto consegue combinar elementos heterogêneos em uma síntese intelectual que não tem a forma de um discurso, mas de uma decisão".

Inquietados por essa forma de diálogo entre escola e pesquisadores, buscamos enquanto integrantes do Observatório Alagoano de Leitura na modalidade Educação de Jovens e Adultos ${ }^{3}$, por meio da pesquisa A leitura e a formação de leitores, no Estado de Alagoas: estudo e intervenção de alfabetização em Educação de Jovens e Adultos ${ }^{4}$, uma metodologia de trabalho que pudesse favorecer efetivamente espaços de aprendizagens entre escola e universidade. E isso desloca a universidade deste lugar de templo do saber. Embora muitos acreditem que tal concepção de universidade seja anacrônica, algumas pesquisas acadêmicas ainda se valem de velhas pretensões para, do alto de sua verdade, dizer o que deve ser feito e como deve ser feito. É um ranço acadêmico, mesmo quando

\footnotetext{
2 Tais críticas não significam um posicionamento de descaso ao empreendimento acadêmico e muito menos um demérito ao rigor para a construção do conhecimento. Ao contrário, a defesa que aqui se faz é por uma modalidade investigativa que no lugar de respostas, priorize as perguntas. Uma tentativa de não silenciar outras vozes.

${ }^{3}$ Atua como dispositivo de formação no ensino superior, especificamente na formação inicial dos estudantes de Pedagogia, e continuada de professores da EJA - atuantes na rede pública de ensino.

4Pesquisa financiada pela Coordenação de Aperfeiçoamento de Pessoal de Ensino Superior (CAPES) Observatório da Educação Edital no 38 de 2010 - com duração de 4 anos (2011-2014).
} 
não verbalizado, de não querer perder seu status quo. A pesquisa em contextos escolares de EJA requer um outro movimento, o que não significa assumir atitudes demagógicas. Certamente que não. O movimento exigido é romper com as zonas de silêncio impostas pela cultura dominante - cujas narrativas sempre as oficiais determinam o que é certo e o que é errado, "produzindo uma gramática fortemente disciplinadora e homogeneizante" (Larrosa, 2010, p.34).

Para tanto, é preciso uma outra leitura dos saberes, sem arremessar os sujeitos para fora. $\mathrm{Ou}$ seja, sem silenciar as suas vozes e negar as suas práticas. E isso é, antes de tudo, uma decisão política. Uma decisão na qual o compromisso ético demanda compreender o sentido epistemológico de se pesquisar nos espaços escolares de EJA. Ao tentar dar visibilidade aos saberes ordinários desta parcela da população, colocada à margem dos benefícios de seu próprio labor, o que se coloca em jogo é a atitude de se estar aberto para ir ao encontro do outro. E para esse encontro é preciso descarrilar-se "destes tempos do possível e do previsível [...] para deixar-se compassar e embalar em um tempo de ida e de volta, um tempo elástico que recusa ser medido e contabilizado" (Larrosa, 2010, p.60). Uma pesquisa, portanto, de outra ordem - que, mantendo o rigor metodológico, não se afirma neste lugar de garantia acadêmica de tudo saber. Por isso, "é preciso cuidado para preencher os silêncios, para completar as faltas, para traduzir os atos, [...] para não silenciar aqueles com quem pretendemos dialogar" (Garcia, 2003, p. 138).

\section{(E)feitos da Pesquisa Colaborativa na Educação de Jovens e Adultos}

Baseadas em vivências realizadas nas atividades do Observatório Alagoano de Leitura em EJA, lançamos mão do corpus de nossa pesquisa em leitura em salas do $1^{\circ}$ segmento de EJA ${ }^{5}$ para refletir sobre uma metodologia de Pesquisa que se constitui, em última instância, como espaço de Formação Colaborativa. Essa pesquisa, cujo foco é o ensino de leitura na modalidade Educação de Jovens e Adultos ${ }^{6}$ - desenvolvida desde 2011, tem nos permitido mergulhar no universo do cotidiano de 4 escolas $^{7}$ da rede pública. Para uma discussão mais amiúde sobre a abordagem metodológica, elegemos, para este artigo, um recorte do corpus construído a partir das situações vividas na Escola Estadual Esmeralda ${ }^{8}$.

Os pressupostos teórico-metodológicos da Pesquisa Colaborativa, implicam a coresponsabilidade, a co-operação e a co-laboração dos sujeitos envolvidos. As ações, que vão sendo desenvolvidas ao longo da pesquisa, afetam não apenas os atores da comunidade escolar, mas os próprios pesquisadores. É essa trama de nós, forjada entre escola e universidade, que dá a dimensão do que de fato se constitui como uma ação colaborativa.

A Pesquisa Colaborativa exige, portanto, um movimento de alteridade entre os participantes, uma vez que as posições não são demarcadas por qualquer tipo de status acadêmico. Ao pesquisador não cabe assumir ares de superioridade ou deslegitimar, em nome de uma crítica exacerbada, o saber do outro. O pesquisador colaborativo está exposto aos imprevistos e aos imponderáveis da dinâmica escolar - deixando-se habitar por uma curiosidade não só epistemológica, mas, sobretudo, ética, pois no lugar de julgar tendenciosamente os acontecimentos, por eles se deixa ser tocado. Entrar neste movimento é deslocar-se da posição de mero investigador para uma posição de sujeito pesquisador

\footnotetext{
${ }^{5}$ Não é nosso propósito neste artigo discutir a prática de ensino da leitura em EJA, embora essa temática seja o escopo de nosso projeto do Observatório de Leitura. Vale esclarecer que nos limitamos, neste artigo, conforme sinaliza o próprio título, a colocar em discussão a metodologia, destacando um episódio de sala de aula para ilustrar os modos de abordagem da pesquisa colaborativa.

${ }^{6}$ Nessa pesquisa, assume-se a definição de leitura na perspectiva de uma dimensão interativa: "Interação verbal entre indivíduos, e indivíduos socialmente determinados: o leitor, seu universo, seu lugar na estrutura social, suas relações com o mundo e os outros" (Soares 2000, p. 18).

${ }^{7}$ Quatro escolas da rede pública de ensino de Maceió, sendo duas municipais e duas estaduais.

${ }^{8}$ Nome fictício de uma escola estadual locus da pesquisa.
} 
também em processo de formação. Afinal, não se pode ter uma "compreensão criativa" (Bakhtin, 1988) sobre o outro quando não se está aberto à mobilização de suas próprias questões.

Para criar laços com os atores sociais da instituição, é necessário estar exposto. Caso contrário, em vez de estar com, torna-se presa fácil da armadilha de falar sobre. Ou seja, silencia-se o outro até mesmo quando a intenção é dar-lhe voz. É do "lugar praticado" que respostas e perguntas se confundem, possibilitando, na perspectiva de Morin (2000), um "pensar complexo" - capaz de aceitar a incerteza, os antagônicos, a dialogicidade etc. Embora princípios práticos e teóricos possam colidir nesta travessia, este "caos" não significa uma desordem por completo. Pelo contrário, ele traz a força da transformação. Como diz Morin (2000, p.104), "a palavra caos tem um sentido muito mais rico, energético, de indistinção e de confusão entre poder criativo e poder destrutivo, e esse caos leva consigo a potencialidade genésica" (Destaque do autor).

Entrar na escola, portanto, acena essa disposição à travessia. Uma passagem que aporta tensões e conflitos de toda ordem. O portão da escola constitui-se a metáfora da mudança, que não é apenas de lugar, mas, sobretudo, de espaço. A passagem por esse portão é o ato simbólico da relação visceral que se pretende manter com a escola, é o gesto de disposição às vicissitudes do cotidiano. Até porque, um dos princípios de uma metodologia colaborativa, na perspectiva de uma formação continuada, vai ao encontro do que diz Freire (1979, p. 52): "a mudança não é trabalho exclusivo de alguns [sujeitos], mas dos [sujeitos] que a escolhem".

É a partir dessa passagem que os sujeitos envolvidos na pesquisa se dispõem à realização do trabalho conjunto e sistemático. E a sistematização está imbricada com os saberes científicos disponibilizados no percurso da pesquisa para a ressignificação das práticas pedagógicas. Uma ressignificação que não está nas mãos de um sujeito em particular, mas de um conjunto de sujeitos que se propõe a pensar uma nova geografia da prática educativa. Segundo Almeida e Sobrinho (2005, p. 01),

Acreditamos que, se quisermos uma escola que atenda à diversidade, precisamos pensar com o outro, precisamos de um processo longo e constante de reflexão com os profissionais que fazem o ato educativo acontecer. Se quisermos mudanças significativas nas práticas convencionais de ensino, precisamos pensar a formação continuada dos educadores.

Sem discursos injuntivos, muitas vezes tão comuns em pesquisas acadêmicas, abre-se o espaço para uma efetiva interação dialógica entre os pares. Ou seja, na perspectiva da práxis ${ }^{9}$, as ações dali resultantes contribuem para a produção de conhecimento, tanto para a comunidade escolar como para comunidade acadêmica. Ao invés de sujeitos de boa vontade ou sujeitos com boas intenções, há o enlace estético e ético entre o saber da experiência e a experiência do saber, que vão se fazendo e refazendo a todo instante. Submetidos a convocações constantes da realidade escolar, os sujeitos não têm como escapar dos efeitos desse funcionamento que reclama, pela sua própria dinâmica, mais questionamentos do que soluções prontas aos movimentos que nela estão implicados. É um efeito constitutivo, inerente aos procedimentos metodológicos que caracterizam uma pesquisa com estatuto de colaborativa. É um outro modo de estar na profissão, uma posição assertiva de emancipar-se pelo conhecimento. Isso significa dizer que

Não devo julgar-me, como profissional, 'habitante' de um mundo de técnicos e especialistas salvadores dos demais, donos da verdade, proprietários do saber, que devem ser doados aos 'ignorantes e incapazes'. Habitantes de um gueto, de onde saio messianicamente para salvar os 'perdidos', que estão fora. Se procedo assim, não me comprometo verdadeiramente como profissional nem como homem. Simplesmente me alieno (Freire, 1981, p.12) (Grifos do autor).

${ }^{9} \mathrm{O}$ conceito de práxis aqui utilizado tem a ver com o conceito freireano da relação teoria/prática. 
Não há, portanto, como negligenciar os acontecimentos que ocorrem no contexto escolar. São acontecimentos que afetam os sujeitos envolvidos na pesquisa. E aqui o pesquisador também não pode eximir-se da condição sujeito, sob pena de nele não operar o processo de formação. É desse modo que a Pesquisa Colaborativa revela o seu lugar de diferença em relação às demais abordagens. Ela abre espaço para as vivências dos sujeitos, sem a preocupação de silenciar os conflitos. Ao contrário, compreende-se que os conflitos e as tensões compõem os espaços de emancipação, numa dimensão transformadora. Daí que cada momento impõe mudanças não apenas no plano de trabalho, mas, principalmente, no próprio modo de pensar dos sujeitos participantes. Como diz Ibiapina (2008), é nesse refletir junto que sentidos e significados são ressignificados, mobilizando, por consequência, novas "artes de fazer" (Certeau, 1994) no contexto escolar e, de modo particular, nas salas de aula. Entretanto, parece que "Nossas categorias de saber ainda são muito rústicas e nossos modelos de análise por demais elaborados para permitir-nos imaginar a incrível abundância inventiva das práticas cotidianas" (Certeau e Giard, 1996, p.342). E é isso que é preciso subverter quando se trata de uma pesquisa colaborativa. Aí está, portanto, a sua (per)feição quando se trata, principalmente, da modalidade de EJA.

\section{Pesquisa Colaborativa e seus procedimentos metodológicos: as vivências na escola e os encontros com os sujeitos de EJA}

Os procedimentos metodológicos da pesquisa colaborativa, tendo em vista a preocupação com a formação dos sujeitos, foram constituídos das seguintes etapas: sessões de observação; sessões de reflexão, sessões de estudo e sessões de (re)planejamento, realizadas sequencialmente - de forma sistemática, conforme o cronograma elaborado com a escola. Todos os professores, que atuam em turmas de EJA, são convidados a fazer parte das sessões de reflexão e de estudo. Todas as sessões são acordadas previamente com a professora da turma e com seus alunos. Os alunos participam apenas das sessões de observação, uma vez que são realizadas na sala de aula. Embora não participem das demais sessões, eles são colocados a par do planejamento como um todo, haja vista que a professora fica, em alguns momentos, ausente da sala, para participar das outras etapas da pesquisa $^{10}$. Cada sessão organiza-se da seguinte forma:

Sessões de observação- são sessões que dizem respeito às observações das aulas, tendo como recurso a filmadora - para realizar a gravação em áudio e vídeo ${ }^{11}$. Essas observações são realizadas uma vez por semana. É solicitado à professora que planeje, a seu modo, uma aula (a primeira aula a ser observada) - cujo foco seja a leitura. As aulas observadas, após a filmagem, são transcritas e armazenadas em CD - fazendo parte do banco de dados da pesquisa. Nas sessões de reflexão, este material torna-se objeto de discussão e análise. Para tanto, alguns episódios de cada aula são selecionados.

Sessões de reflexão - Nestas sessões, conforme dito anteriormente, é o momento de assistir e refletir sobre alguns episódios das aulas da professora. A gravação em áudio e vídeo se mostra um recurso metodológico muito interessante e significativo - forjada como uma atividade estética. E, como diz Bakhtin (2008, p. 26), “(...) a atividade estética pressupõe um "excedente de visão”. A própria professora pode se ver-vendo - criador e criatura - estabelecendo, através da imagem reproduzida, um movimento de alteridade. Falar sobre si, sobre suas aulas filmadas - colocando-se

\footnotetext{
${ }^{10}$ Nesses días em que a professora está ausente da sala, os alunos têm das aula de informática.

11 A filmadora fica armada em tripé - deixando o bolsista com liberdade para fazer quaisquer outras anotações sobre a aula, quando necessário. Nos momentos de observação, não há nenhum tipo de interferência do bolsista à aula.
} 
numa outra posição, equivale a se deslocar, se tornar um outro em relação a si mesmo. Uma espécie de "visão exotópica" (Bakhtin, 2008) ${ }^{12}$. Após assistir episódios de suas aulas, junto com os demais participantes da pesquisa - gestores, professores de EJA da escola, bolsistas e os professores pesquisadores, a professora faz as primeiras pontuações - livremente. A partir de sua fala, outros participantes também têm a oportunidade de fazer as suas colocações, procurando destacar aspectos da aula que mais chamaram atenção. É um momento de diálogo, em que todos podem se (re)ver. Não apenas a professora, cuja aula está em foco, mas todos ali presentes - oportunidade de pensar sobre as próprias aulas (no caso, os outros professores de EJA); de pensar sobre o planejamento pedagógico voltado para os sujeitos de EJA; de pensar sobre as questões teóricas, que ali, naquela aula e no próprio diálogo fomentado pelos pares, se revelam em latência. É um movimento discursivo elaborado coletivamente. Nessa direção, Desgagné (2007. p. 11) afirma que o investigador "[...] deve privilegiar, acima de tudo, as competências ${ }^{13}$ do ator em contexto" (grifo do autor). Ou seja, procurar "com eles, no interior do contexto em que atuam, compreender em que se apoia esse agir" (grifos do autor). Assim, as análises, possibilitadas no/pelo diálogo, suscitam a busca de leituras teóricas que possam contribuir com a temática que se apresenta como objeto de estudo.

Sessões de estudos - Nessas sessões, as discussões são de ordem mais teórica. Os textos selecionados, antecipadamente, são escolhidos tendo como critério o interesse e as necessidades da professora da turma - sujeito da pesquisa. Portanto, a etapa de co-operar acontece por meio dessas sessões de estudo - que se constituem em encontros de diálogos. Mas os diálogos nesse momento são pautados sobre o quadro conceitual, possibilitando análises aprofundadas do objeto de estudo e, consequentemente, construção de novas ideias. Não por outra razão, Ibiapina (2008, p.22) vai dizer que a pesquisa colaborativa traz significativas contribuições “(...) para a concretização dos ideais de formação e desenvolvimento profissional e de produção de teorias mais próximas dos anseios sociais de mudança da sala de aula, da escola e da sociedade". E isso se torna possível, sobretudo, pelos diferentes saberes que se cruzam nessas sessões de estudo sobre determinados conceitos teóricos. Isso implica, certamente, abrir espaços para questionamentos, dúvidas e confrontos. Ou seja, "Esse processo implica em conflitos propiciadores de oportunidades de compreensão crítica por parte dos envolvidos sobre o que está sendo discutido" (Ibiapina e Ferreira, 2005, p. 33). Nesse caso, uma voz não se sobrepõe à outra. Todos os partícipes apresentam sua compreensão em relação ao texto lido, ancorados em suas experiências pedagógicas e acadêmicas. Segundo Pimenta (2009, p.29), “(...) é num processo de troca de experiências que os professores constituem seus saberes como praticum, ou seja, uma reflexão constante na e sobre a prática".

Sessão de (re)planejamento - estas sessões funcionam como um feedback das sessões anteriores. $\mathrm{O}$ (re)planejamento revela que a pesquisa colaborativa tem como matriz uma perspectiva dialética cuja dinâmica se constitui como um processo de aprendizagem voltado à práxis, em que teoria e prática complementam-se e tranformam-se, sistematicamente. Uma ação para a mudança da realidade do cotidiano e da cultura escolar no qual estão imersos. Afinal, todos se constituem partícipes para que algo novo, a partir da ressignificação de sentidos, possa deflagrado na dinâmica da prática pedagógica (Ibiapina, 2008). Nas sessões de (re) planejamento novas decisões são tomadas

$12 \mathrm{O}$ Eu se constitui através do Outro, pois é na interação com o Outro que se tem a possibilidade de um acabamento, ainda que provisório. Ver-se como Outro é um exercício de alteridade, o que Bakhtin denominou como exotopia - um excedente de visão, isto é, um desdobramento de olhares a partir de um lugar exterior.

${ }^{13}$ O termo competência refere-se ao sentido utilizado por Giddens (1987, p.12) “[..] na capacidade de qualquer ator social em exercer seu julgamento e orientar a tomada de decisão em função das condições que prevalecem e daquilo que está em jogo, no contexto de sua ação específica" 
em relação às aulas a serem dadas - voltadas para leitura, assim como outros textos são sugeridos para sessões de estudo.

\section{O local da pesquisa: caracterização do espaço e dos sujeitos}

Conforme dito anteriormente, o estudo teve como lócus a Escola Estadual Esmeralda, situada em Maceió. Possui uma estrutura física relativamente pequena, na qual abriga o Ensino Fundamental $\left(1^{\circ}\right.$ ao $4^{\circ}$ ano), nos períodos diurnos; e a modalidade de Educação de Jovens e Adultos $\left(1^{\circ}\right.$ segmento - alfabetização e pós-alfabetização), no período noturno. As poucas salas existentes na escola, no total de quatro, são amplas, ventiladas e bem iluminadas. Há também um espaço destinado à sala de leitura, onde se encontram diversos acervos literários.

O pátio, embora pequeno, é bastante aconchegante. É nesse espaço em que se realizam os eventos e outros tipos de atividades pedagógicas. O pátio faz a divisa entre as salas de aula e as demais salas, que são ocupadas pela Direção, Coordenação Pedagógica, Sala de Leitura e Sala dos Professores.

Os jovens e adultos dessa escola são pessoas de baixo poder aquisitivo. Moram em bairros da periferia ou na favela vicinal à escola. Muitos deles vieram do interior do Estado. Por diferentes razões, de ordem econômica e social, são alunos que não puderam completar sua escolarização no tempo considerado, por lei, como ideal. $\mathrm{Na}$ sala observada, prevalece um maior número de mulheres. Elas atuam, muitas vezes sem carteira assinada, como babás e/ou empregadas domésticas. Mas a grande maioria é apenas "do lar".

Quando indagados sobre os motivos de regressarem aos estudos, os alunos alegam que a escolaridade pode possibilitar ascensão social. Nisso se inclui a conquista de um emprego que lhes garantam todos os direitos trabalhistas, bem como a possibilidade de aquisição da casa própria. Eles acreditam, assim, que esse tipo de status social pode valorizá-los como cidadãos.

A professora tem formação em magistério ${ }^{14}$ (Escola Normal - Ensino Médio). $\mathrm{Na}$ graduação, não concluiu o curso de Licenciatura em Ciências Biológicas. Além do trabalho como professora da rede pública, atuando na sala de EJA, também é funcionária de um Posto de Saúde. Já fez inúmeros vestibulares para o curso de enfermagem, mas não obteve sucesso. Após atuar, durante dois anos, como professora do $3^{\circ}$ ano do ensino fundamental, resolveu assumir uma turma de EJA mais por conveniência de horário do que, na verdade, por identidade com essa modalidade de ensino. A professora sempre recusou as formações continuadas oferecidas pela $13^{\text {a }}$ Coordenadoria de Regional de Ensino (CRE) $)^{15}$, uma vez que elas se mostravam distantes da realidade da escola. No entanto, mostrou entusiasmo com a chegada da pesquisa na escola, comprometendo-se a participar das atividades propostas.

Para ilustrar o movimento vivido na escola Esmeralda, será descrito um episódio da sessão de reflexão - que se constitui numa das etapas da metodologia da pesquisa - para dar a visibilidade aos momentos de narrativa, problematização e diálogo - tríade na qual se sustenta a experiência dessa pesquisa.

É a partir desses lugares enunciativos dos sujeitos envolvidos onde se mobilizam as leituras possíveis. Nesse sentido, a sessão de reflexão constitui-se como "espaço de criação de novas relações entre a teoria e a prática, permitindo que o professor compreenda o que, como e o porquê das suas ações" (Ibiapina, 2008, p. 97). Do ponto de vista do encaminhamento metodológico, as sessões de reflexão se repetem quinzenalmente, intercaladas com aulas gravadas pelos bolsistas ${ }^{16}$. As

\footnotetext{
14 No ano de 2012, a professora passou no vestibular para licenciatura em Pedagogia.

15 Órgão responsável pela formação continuada dos professores que atuam na Escola Esmeralda.

16 A gravação feita pelos bolsistas -alunos do curso de graduação de Pedagogia, selecionados previamente para fazer parte da pesquisa - foi uma negociação com a professora - sujeito da pesquisa, considerando seu
} 
aulas gravadas e o estudo de textos acerca do ensino da leitura ${ }^{17}$ se dão, nessas sessões de reflexão, dentro de continuum. O estudo dos textos, escolhidos em parceria, é também o momento de ler com os outros. Há algo da ordem da repetição nesse movimento de ler um texto nas sessões de reflexão e de ler um texto em sala de aula, em virtude de ser a leitura o fio condutor nesse processo formativo.

Nesse sentido, as sessões de reflexão se constituem como espaço de formação. Ao assistir as próprias aulas (já gravadas), no encontro coletivo, os diálogos terminam por mobilizar atitudes de curiosidade epistemológica que isoladamente não possibilitaria maiores consequências. A narração daí advinda constitui-se o ponto inicial da sessão de reflexão. Por meio da narrativa provocada, o docente tem a oportunidade de (re)ver sua metodologia, suas tomadas de decisão para o ensino da leitura. Essa visão exotópica de seu trabalho, compartilhada com outros olhares, não menos curiosos epistemologicamente, é a via de acesso ao momento da problematização. A partir dessa problematização provoca-se um espaço de confronto - instituição do processo dialógico, que levado ao limite se impõe como práxis (ação-reflexão-ressignificação).

Essa experiência estética do docente sobre sua própria prática pedagógica, refletindo criticamente com os pesquisadores da universidade, colabora com o redimensionamento de sua prática pedagógica tanto em relação aos procedimentos didático-metodológicos como em relação aos critérios de escolha de seus materiais - no caso, os gêneros textuais que subsidiam o ensino da leitura em sala de aula. Todo esse exercício de escuta e olhar da professora - narrando, contando e falando sobre sua prática - trouxe a possibilidade de mostrar-se para o outro, de aceitar-se exposto para o outro, ainda que ele não se faça mais presente. Ao retornar para a sala de aula, a professora na verdade não leva um modelo de aula. Ela leva algo que ressoa no silêncio das vozes que não mais estão lá enquanto presença - seja a palavra do outro, seja o que ressoa do texto lido ou das imagens veiculadas. Ou seja,

$\mathrm{Na}$ formação, como na experiência estética, a relação com a matéria de estudo é de tal natureza que, nela, alguém se volta para si mesmo, alguém é levado para si mesmo. E isso não é feito por imitação, mas por algo assim como por ressonância (Larrosa, 2010, p.50).

Mas vale dizer que todos os sujeitos, tanto a equipe escolar como a equipe da universidade, ali se expõe ao exercício da palavra - como arte de forjar conceitos - possibilitando encontro de corpos, de sensibilidades, de sentimentos, de culturas e de pensamentos - espaço propício para que o sujeito seja percebido em sua singularidade. As sessões de reflexão oportunizam, a partir das interações dialógicas, atitudes criativas para produzir novos conhecimentos e novas ações.

\section{A leitura das possibilidades: o que se aprende quando se opera uma escuta}

Em um contexto de observação assistimos a uma aula planejada pela professora. Ela introduz sua aula mostrando aos alunos a música que havia escolhido para trabalharem naquele dia. A música é Maria, Maria, de Milton Nascimento (http://musica.com.br/artistas/miltonnascimento $/ \mathrm{m} /$ maria-maria/letra.html). Sua intenção foi explorar a leitura. Para tanto, propôs a seguinte sequência didática:

pedido para que as pesquisadoras não estivessem na sala de aula, pelo menos nos primeiros meses da pesquisa na escola. O fato das pesquisadoras não estarem ali, segundo ela, facilitaria sua espontaneidade durante as filmagens. Sua relação com a bolsista parecia mais à vontade. Levando em conta os princípios da pesquisa colaborativa, foi possível compreender que a professora precisava desse tempo para superar sua "resistência" à presença das pesquisadoras.

${ }_{17}$ Para as sessões de reflexão, alguns textos são selecionados, junto com os professores, para dar o mote das discussões que se fazem necessárias à compreensão da concepção de leitura adotada no projeto. 
Levantamento dos conhecimentos prévios dos alunos, a partir da problematização do título da música;

Produção de um texto coletivo no quadro, com registros dos conhecimentos prévios levantados pelos alunos;

Oralização do texto da música pela professora;

Leitura silenciosa do texto da música pelos alunos;

Leitura coletiva da música;

Discussão da letra da música;

Relação entre o texto produzido coletivamente pelos alunos e a música;

Escuta da música;

Canto da música pelos alunos

A disposição metodológica na pesquisa colaborativa é empreender, sobretudo, um movimento de alteridade, o que exige colocar-se no lugar do outro. Ou seja, procurar compreender o que das sessões de reflexão a professora já pode fazer escuta, e isso, em grande medida, constituise como aprendizado. Impor o exercício do contrário para a nossa reflexão é também se permitir ao movimento do não saber. É fazer uma escuta desvencilhada de qualquer tipo de certeza.

No momento da narração, após assistir na tela sua própria aula, a professora demonstrou que teve a preocupação de planejar sua aula, revelando sensibilidade na escolha de um gênero textual, no caso a música popular brasileira, que motivasse os alunos à leitura por conta da identificação com a história da personagem que nomeia o título da canção. O levantamento dos conhecimentos prévios, realizado com os alunos, revela que a professora tem por intenção dar voz aos alunos. Ou seja, compreende que é preciso se aproximar da realidade de seus alunos para que a atividade possa produzir sentido. Além disso, a professora também demonstra compreender que esses saberes devem ser socializados para que outros saberes coloquem-se em jogo. A produção escrita de um texto coletivo revela que a professora mostra-se sensível à autoria de seus alunos, à valorização de suas palavras próprias. Quando questionada sobre a sua opção de ler em voz alta a letra da música, a professora respondeu enfaticamente que foi a oportunidade de emprestar seu tom poético, pela sua experiência de leitura, como referência para seus alunos. É compreender que seus alunos precisam ouvir para ouvir-se. O ouvir-se que é da ordem de um instante. Dar como oferenda a magia de uma palavra escutada que, possivelmente, irá ressoar com e em outros textos. E por aí a professora caminhou na sequência didática de sua aula, procurando, ao máximo, que os alunos sentissem a música por inteiro até chegar à escuta e ao canto da música. E ela encerra não com a voz do cantor, mas com a voz dos alunos.

Ao levar para a sala de aula a música, enquanto um gênero textual, a professora revela-se aberta ao diálogo nas sessões de reflexão com os pesquisadores. No lugar de resistir, ela opta por ousar - elaborando um tipo de aula que, até então, não fizera parte de seu(s) plano(s). Ousadia no sentido de se permitir fazer o novo - assumindo os riscos de suas escolhas. Nada se disse à professora sobre qual seria o texto ideal para levar à turma. Durante as sessões de reflexão muito se discutiu sobre os sujeitos de EJA, a saber: qual a finalidade daquilo se ensina numa sala de EJA? O que de fato é importante para os jovens e adultos aprenderem em seu processo de escolarização? Qual o lugar que eles têm na escola? São perguntas que não esperam respostas. Muito menos respostas prontas. Poderíamos até dizer que são perguntas sem respostas. Elas têm o propósito, tão somente, de fazer provocações. As perguntas inquietam e suspendem as certezas, permitindo que se assuma uma atitude de ação-reflexão-ação.

$\mathrm{Na}$ sessão de reflexão, a professora pode ainda falar sobre o que a motivou à escolha daquela música de Milton Nascimento. E ela responde com espontaneidade: "Procuramos a tarde inteira um 
texto para trabalhar a intertextualidade, como vocês falaram na sessão anterior. E essa música poderia fazer intertextualidade".

É importante notar que a escolha da música deu-se pela curiosidade epistemológica e por um desejo da professora de viver uma experiência numa dimensão mais estética. Daí a sensibilidade de uma escuta - ambas proporcionadas pelas sessões de reflexão. Nessas sessões, procurou-se chamar atenção para a necessidade de trazer, por meio das diversas linguagens, sobretudo a poética, lugares de ancoragens para os dizeres dos alunos - sua realidade, seu cotidiano. Nesse sentido, a professora trouxe a música, conforme depoimento à época, em virtude de sua turma ser composta por mulheres em sua maioria. Além disso, a letra da música convocou, inclusive, o interesse de ela em explorar um aspecto que lhe pareceu bastante significativo, a saber: intertextualidade - uma categoria nova para o seu modo de ensinar. É a palavra intertextualidade que a convoca para um repensar de sua aula Assim, a escolha da música revela uma escuta. Uma escuta contingente, mas bastante aguçada. Compreendemos que essa escolha da música, mais do que a riqueza intertextual, demonstra, sobretudo, um olhar para os alunos como leitores.

De fato, na letra de Maria, Maria converge termos políticos e religiosos. Há a presença de versículos da bíblia provocando uma intertextualidade e uma riqueza de sentidos para a leitura da poesia que encerra no texto. É o caso, por exemplo, do nome Maria que remete ao nome da mãe de Jesus e, ao mesmo tempo, pode se prestar a ser uma homenagem à mulher brasileira cujos esforços a colocam como uma mulher de garra e coragem perante às situações enfrentadas no dia a dia. Uma mulher de fibra mesmo nos momentos de dor.

A partir da música os alunos poderiam ser provocados ao diálogo, à interação. Assim, ela mesma diz: "a reflexão ia chegar mais perto da realidade deles". E ainda complementa: "Há muitas mulheres na sala".

Considerando o propósito da intertextualidade almejada pela professora, vejamos o texto produzido coletivamente em sala de aula e registrado pela professora, com base no levantamento dos conhecimentos prévios dos sujeitos:

Quadro 1 - Texto produzido coletivamente em sala de aula MARIA A VITORIOSA MARIA ACORDA CEDO, PREPARA O CAFÉ. ACORDA AS CRIANÇAS, DÁ CAFÉ, LEVA PARA A ESCOLA E DEPOIS COMEÇA A LAVAR AS ROUPAS DE GANHO. ENQUANTO TRABALHA ELA ESCUTA AMADO BATISTA, SEU CANTOR PREFERIDO.

DEPOIS, ELA PREPARA O ALMOÇO. SEU MARIDO CHEGA PARA ALMOÇAR E MAL LHE DIRIGE A PALAVRA. MARIA FICA CHATEADA, POIS ESPERAVA MAIS ATENÇÃO. AS CRIANÇAS CHEGAM DA ESCOLA, ALMOÇAM E VÃO BRINCAR. ELA PENSA EM IR AO SHOPPING TOMAR SORVETE COM OS FILHOS E ESQUECER OS PROBLEMAS, AS ENFERMIDADES... SEU MAIOR SONHO É VIAJAR PARA FERNANDO DE NORONHA! MARIA DESEJA QUE SEU MARIDO MUDE, SEJA MAIS CARINHOSO COM ELA, LHE DÊ MAIS ATENÇÃO...

SEU MAIOR SONHO É VOLTAR A ESTUDAR E CONQUISTAR O SEU ESPAÇO, TER UM EMPREGO MELHOR PARA DAR UM FUTURO MELHOR AOS FILHOS.

Texto transcrito do quadro de giz pela bolsista

Nessa produção coletiva, os alunos nomearam o texto de Maria a Vitoriosa. Tal nomeação já revela que houve por parte dos alunos uma escuta para os sentidos da leitura do texto. De forma temporal e gradativa, os sujeitos foram narrando o cotidiano de uma "Maria", inspirados pela escuta música de Milton Nascimento. Não se tratava de qualquer Maria, mas “A vitoriosa”. É possível perceber os efeitos da sequência didática, planejada pela professora, fazendo efeito na escuta dos alunos. Um efeito de efeito, pois o seu desejo, tal como ela mesma diz, era "levar a intertextualidade" para os alunos. E os alunos são tocados por esse mundo de Maria. Mundo por 
eles vivenciado: mulheres, mães, analfabetas, ou não, que frequentam a Educação de Jovens e Adultos. Eles são atravessados, de modo singular, pela substância poética do texto.

Ao perguntarmos na sessão de reflexão se algo a tinha deixado insatisfeita no planejamento de suas aulas, ela se adianta para dizer: "Precisei repetir várias vezes a música para que eles montassem a música fatiada". Talvez a professora tenha planejado atividades em excesso, fazendo uma regressão ao seu lugar de professora que precisa alfabetizar seus alunos por meio de exaustivos exercícios. A possível dificuldade dos alunos para realizar o exercício de montagem, seja apenas uma sinalização de que ela atividade era "demais". Poder se escutar em relação aos seus excessos, é dar voz à professora em relação aos seus enganos. De acordo com Ibiapina (2008), as sessões de reflexão reconstroem a gênese do próprio significar a partir da linguagem reflexiva do outro. As sessões de reflexão têm nos mostrado que devem ser sistematizadas:

[...] com a finalidade de auxiliar os professores a reconstruir conceitos e práticas, desenvolvendo um processo reflexivo que inicia pelas construções já existentes e pela identificação dos componentes básicos dos eixos teóricos da ação e as tendências que estão mais próximas do fazer didático. Essa reflexão promove a reelaboração de conceito e práticas pedagógicas e a avaliação das possibilidades de mudanças da atividade docente (Ibiapina, 2008, p. 97).

Outro ponto de destaque consiste no fato de que as sessões de reflexão vêm suscitando ao professor inúmeras curiosidades epistemológicas sobre a natureza, especificidades e cultura escolar de vivências de práticas de ensino da leitura, muitas vezes, descontextualizadas e esvaziadas de sentido. Dessa forma, a pesquisa colaborativa tem se colocado como uma possibilidade de se (re)pensar, num processo de formação continuada, o movimento didático da prática de ensino da leitura para os sujeitos da EJA.

\section{Conclusão}

A partir das colocações expostas pode-se dizer que a pesquisa colaborativa, levando em conta seus fundamentos epistemológicos e procedimentos metodológicos, possibilita uma relação mais comprometida entre universidade e escola, especialmente quando se trata de uma atividade investigativa que privilegia os movimentos de alteridade. Nem sempre uma atividade investigativa, sobretudo aquelas que (per)seguem um modelo positivista de ciência, procurando, pelos modos de abordagem, tudo colocar sob controle, provoca aproximações entre os sujeitos nela implicados.

Ao longo desses últimos dois $\operatorname{nnos}^{18}$, nos quais se vêm desenvolvendo a pesquisa junto a professores de EJA - em seu próprio contexto escolar, é possível perceber o modo pelo qual se instaura um processo de formação continuada, envolvendo os sujeitos da pesquisa como um todo. Tal como descrito no episódio de uma de sessão de reflexão, as situações vivenciadas, ao tempo em que apontam para o conjunto de decisões coletivas, revelam que muitas mudanças são operadas quando se permite estar com o outro, negociar com o outro e se expor ao outro. Muito mais do que preocupar-se com repostas, a pesquisa colaborativa se ocupa das perguntas problematizadoras. Isto porque ela tem como um de seus objetivos a construção de uma cultura colaborativa na escola, em que os estudos e a troca de ideias sejam uma constante entre os pares da instituição.

A pesquisa colaborativa tem nos permitido a possibilidade de se repensar coletivamente a prática de ensino da leitura na EJA com o intuito de (re)significá-la, uma vez que segundo

\footnotetext{
${ }^{18}$ Esta pesquisa, financiada pela CAPES, será desenvolvida no período de 2011 a 2015.
} 
Cavalcante (2009) as práticas de leitura e compreensão de texto na EJA tem se constituído em momentos individuais e sem significados.

Portanto, uma pesquisa configurada por uma rede imbricada de ações coletivas, da qual não se pode sair imune aos seus (e)feitos. E é justamente o espaço de diálogo e de encontro - noções fundantes numa práxis colaborativa, que coloca em destaque a (per) feição dessa pesquisa junto aos docentes da modalidade de Educação de Jovens e Adultos (EJA), que tomou como foco o ensino da leitura. Uma pesquisa colaborativa - na perspectiva da formação continuada - que na troca de reflexões e inquietações indicia um processo emancipatório.

\section{Referências}

Bakhtin, M. (2003). Estética da criação verbal. São Paulo: Martins Fontes.

Bakhtin, M. (Voloschinov) (1988). Marxismo e Filosofia da Linguagem. São Paulo: HUCITEC.

Cavalcante, V. C. (2009). Leitura na educação de jovens e adultos: um estudo de eventos e práticas de letramento em salas de aula do $1^{\circ}$ segmento. Dissertação de mestrado. Programa de PósGraduação em Educação Brasileira, Universidade Federal de Alagoas, Maceió.

Certeau, M. de.(1994). A invenção do cotidiano: 1 Artes de Fazer. Petrópolis: Vozes.

Certeau, M.; Giard, L. Uma ciência prática do singular. In: Certeau, M. et alii. A invenção do cotidiano 2: morar, cozinhar. Petrópolis: Vozes, 1996.

Desgagné, S. (2007). O conceito de pesquisa colaborativa: a ideia de uma aproximação entre pesquisadores universitários e professores práticos. Revista Educaşão em Questão. Natal, v. 29, n. 15 pp. 7-35, maio-agosto.

Freire. P. (1979). Educação como prática da liberdade. Rio de Janeiro: Paz e Terra.

Freire. P. (1981). Educação e Mudança. Rio de Janeiro: Editora Paz e Terra.

Freire. P. (2006). Pedagogia da autonomia: saberes necessários à prática educativa. 34. ed. São Paulo: Paz e Terra.

Garcia, R. L. (2003). A difícil arte/ciência de pesquisar com o cotidiano. In: Garcia, R. L. (org.). Método; Métodos; Contramétodo. São Paulo: Cortez.

Giddens, Anthony (1987). La constitution de la societé. Paris: Presses Universitaires de France.

Ibiapina, I. M. L. de M. (2008). Pesquisa colaborativa: investigação, formação e produção de conhecimento. Brasília: Liber Livro Editora.

Ibiapina, I. M. L. de M.; Ferreira, Maria. Salonilde. A pesquisa colaborativa na perspectiva sóciohistórica. Linguagem, Educação e Sociedade, Teresina, n.12, 2005, p. 26-38.

Jesus, D. M.; Almeida, M. L.; Sobrinho, R. C. (2005). Pesquisa-ação-crítico colaborativa: implicações para a formação continuada e a inclusão escolar. $28^{a}$ Reunião Anual da Anped, Caxambu-MG, 2005, v.1, p.1-20.

Larrosa, J. (2010). Pedagogia profana: danças, piruetas e mascaradas. Belo Horizonte: Autêntica.

Morin, Edgar. (2000). A cabeça bem-feita: repensar a reforma, reformar o pensamento. Rio de Janeiro: Bertrand Brasil.

Pimenta, Selma Garrido . Pesquisa-ação Crítico-colaborativa: construindo seu significado a partir de experiências com a formação docente. Revista Educação e Pesquisa, São Paulo, v. 31, p. 521539, set./dez. 2005

Soares, M. (2000). As condições sociais da leitura: uma reflexão em contraponto. In: Zilberman, R.; Silva, E. T. (2000). (Org.). Leitura: perspectivas disciplinares. São Paulo: Ática. 


\section{Sobre as Autoras}

\section{Marinaide Lima de Queiroz Freitas}

Afiliação: Professora Adjunta da Graduação em Pedagogia e da Pós-graduação em Educação Brasileira (PPGE/UFAL), nas linhas de História e Política e Educação e Linguagem naide12@hotmail.com

Informação biográfica: A autora é pesquisadora da Educação de Jovens e Adultos. Líder do Grupo de Pesquisa (CNPq) Multidisciplinar em Educação de Jovens e Adultos (MULTIEJA). Membro do Núcleo de Estudos, Pesquisa e Extensão em Alfabetização (NEPEAL). Coordenadora do Observatório Alagoano de Leitura em EJA, financiado pela CAPES e coordenadora também do Programa de Cooperação Acadêmica (PROCAD/Casadinho) entre as Universidade Federal de Alagoas (UFAL), Universidade do Estado do Rio de Janeiro e a Universidade Federal do Rio Grande do Norte (UFRN).

\section{Nadja Naira Aguiar Ribeiro}

Afiliação: Professora do Programa de Pós-graduação em Educação (PPGE), na linha de Pesquisa Educação e Linguagem e do Curso de Pedagogia do Centro de Educação da Universidade Federal de Alagoas (UFAL) nnaguiar@gmail.com

Informações bibliográficas: A autora é pesquisadora no campo da educação de jovens e adultos, atuando na formação de pedagogos. É líder do Grupo de Pesquisa (CNPq) Teorias e Práticas em Educação de Jovens e Adultos. No momento é integrante do Observatório Alagoano de Leitura em EJA, financiado pela CAPES e integrante do Programa de Cooperação Acadêmica (PROCAD/Casadinho) entre a Universidade Federal de Alagoas (UFAL), a Universidade do Estado do Rio de Janeiro e a Universidade Federal do Rio Grande do Norte (UFRN).

\section{Sobre as Editoras Convidadas}

\section{Sandra Regina Sales}

Professora do Programa de Pós-Graduação em Educação, Contextos Contemporâneos e Demandas Populares (PPGEduc) na linha de pesquisa Educação e Diversidades Étnico-Raciais e do Departamento Educação e Sociedade da Universidade Federal Rural do Rio de janeiro. sandrasales@ufrrj.br Informação biográfica: A autora é pesquisadora nos campos da Educação de Jovens e Adultos, Mídia e Educação e Políticas de Ação Afirmativa no Ensino Superior. Integra o Grupo de Pesquisa (CNPq) Políticas de trans-formação: pesquisas em educação e comunicação, do qual é líder, e o Laboratório de Estudos Afro-brasileiros - LEAFRO. Atualmente desenvolve as pesquisas $A$ EJA e a diversidade na mídia: uma análise das representações dos sujeitos, dos atores e das políticas educacionais nas revistas semanais brasileiras e Que educação para que cidadão? Discursos influentes na Educação de Jovens e Adultos no Brasil (1995-2013). É co-organizadora do livro Educação de Jovens e Adultos: políticas e práticas educativas (2011) e tem publicado artigos em revistas e capítulos de livros nas áreas de pesquisa nas quais atua.

\section{Jane Paiva}

Professora do Programa de Pós-Graduação em Educação (ProPEd), na Linha de Pesquisa Educação Inclusiva e Processos Educacionais e do Curso de Pedagogia da Faculdade de Educação da Universidade do Estado do Rio de Janeiro (UERJ). janepaiva@terra.com.br 
Informação biográfica: A autora é pesquisadora no campo da educação de jovens e adultos, atuando na formação de pedagogos e de novos pesquisadores - mestres e doutores. É líder do Grupo de Pesquisa (CNPq) Aprendizados ao longo da vida: sujeitos, politicas e processos educativos. No momento desenvolve a pesquisa integrada (com a Universidade Estadual de Campinas e a Universidade Federal de Juiz de Fora) Diagnóstico da qualidade de ensino na educação de jovens e adultos: um estudo de caso nos municípios de Campinas, Juiz de Fora e Rio de Janeiro, financiada pelo Edital Observatório da Educação, da CAPES/INEP; e coordena as ações do projeto de pesquisa e extensão do Centro de Referência e Memória da Educação Popular e da Educação de Jovens e Adultos (CReMEJA). Autora de artigos em revistas e capítulos de livros no campo.

\title{
DOSSIÊ EJA II
}

\section{arquivos analíticos de políticas educativas}
Volume 22 Número 64
30 de junho de 2014
ISSN 1068-2341

\begin{abstract}
(c)
SORERTIGHISRESERED O Copyright e retido pelo/a o autor/a (ou primeiro co-autor) que outorga o direito da primeira publicação à revista Arquivos Analíticos de Políticas Educativas. Más informação da licença de Creative Commons encontram-se em http://creativecommons.org/licenses/by-nc-nd/2.5. Qualquer outro uso deve ser aprovado em conjunto pelo/s autor/es e por AAPE/EPAA. AAPE/EPAA é publicada por Mary Lou Fulton Institute Teachers College da Arizona State University. Os textos publicados em AAPE são indexados por CIRC (Clasificación Integrada de Revistas Científicas, Espanha) DIALNET (Espanha),Directory of Open Access Journals, Education Full Text (H.W. Wilson), EBSCO Education Research Complete, , ERIC, , QUALIS A2 (Brasil), SCImago Journal Rank; SCOPUS, SOCOLAR (China). Contribua com comentários e sugestões a http://epaa.info/wordpress/ ou para Gustavo E. Fischman fischman@asu.edu.
\end{abstract}

Curta a nossa comunidade EPAA's Facebook https://www.facebook.com/EPAAAAPE e Twitter feed @epaa_aape. 


\section{arquivos analíticos de políticas educativas conselho editorial}

Editor: Gustavo E. Fischman (Arizona State University)

Editores Associados: Rosa Maria Bueno Fisher e Luis A. Gandin

(Universidade Federal do Rio Grande do Sul)

Dalila Andrade de Oliveira Universidade Federal de Minas Gerais, Brasil

Paulo Carrano Universidade Federal Fluminense, Brasil

Alicia Maria Catalano de Bonamino Pontificia Universidade Católica-Rio, Brasil

Fabiana de Amorim Marcello Universidade Luterana do Brasil, Canoas, Brasil

Alexandre Fernandez Vaz Universidade Federal de Santa Catarina, Brasil

Gaudêncio Frigotto Universidade do Estado do Rio de Janeiro, Brasil

Alfredo M Gomes Universidade Federal de Pernambuco, Brasil

Petronilha Beatriz Gonçalves e Silva Universidade Federal de São Carlos, Brasil

Nadja Herman Pontificia Universidade Católica -Rio Grande do Sul, Brasil

José Machado Pais Instituto de Ciências Sociais da Universidade de Lisboa, Portugal

Wenceslao Machado de Oliveira Jr. Universidade Estadual de Campinas, Brasil
Jefferson Mainardes Universidade Estadual de Ponta Grossa, Brasil

Luciano Mendes de Faria Filho Universidade Federal de Minas Gerais, Brasil

Lia Raquel Moreira Oliveira Universidade do Minho, Portugal

Belmira Oliveira Bueno Universidade de São Paulo, Brasil

António Teodoro Universidade Lusófona, Portugal

Pia L. Wong California State University Sacramento, U.S.A

Sandra Regina Sales Universidade Federal Rural do Rio de Janeiro, Brasil

Elba Siqueira Sá Barreto Fundação Carlos Chagas, Brasil

Manuela Terrasêca Universidade do Porto, Portugal

Robert Verhine Universidade Federal da Bahia, Brasil

Antônio A. S. Zuin Universidade Federal de São Carlos, Brasil 


\section{education policy analysis archives editorial board}

Editor Gustavo E. Fischman (Arizona State University)

Associate Editors: Audrey Amrein-Beardsley (Arizona State University), Rick Mintrop, (University of California, Jeanne M. Powers (Arizona State University)

Jessica Allen University of Colorado, Boulder

Gary Anderson New York University

Michael W. Apple University of Wisconsin, Madison

Angela Arzubiaga Arizona State University

David C. Berliner Arizona State University

Robert Bickel Marshall University

Henry Braun Boston College

Eric Camburn University of Wisconsin, Madison

Wendy C. Chi* University of Colorado, Boulder

Casey Cobb University of Connecticut

Arnold Danzig Arizona State University

Antonia Darder University of Illinois, UrbanaChampaign

Linda Darling-Hammond Stanford University

Chad d'Entremont Strategies for Children

John Diamond Harvard University

Tara Donahue Learning Point Associates

Sherman Dorn University of South Florida

Christopher Joseph Frey Bowling Green State University

Melissa Lynn Freeman* Adams State College

Amy Garrett Dikkers University of Minnesota

Gene V Glass Arizona State University

Ronald Glass University of California, Santa Cruz

Harvey Goldstein Bristol University

Jacob P. K. Gross Indiana University

Eric M. Haas WestEd

Kimberly Joy Howard* University of Southern California

Aimee Howley Ohio University

Craig Howley Ohio University

Steve Klees University of Maryland

Jaekyung Lee SUNY Buffalo
Christopher Lubienski University of Illinois, UrbanaChampaign

Sarah Lubienski University of Illinois, UrbanaChampaign

Samuel R. Lucas University of California, Berkeley

Maria Martinez-Coslo University of Texas, Arlington

William Mathis University of Colorado, Boulder

Tristan McCowan Institute of Education, London

Heinrich Mintrop University of California, Berkeley

Michele S. Moses University of Colorado, Boulder

Julianne Moss University of Melbourne

Sharon Nichols University of Texas, San Antonio

Noga O'Connor University of Iowa

João Paraskveva University of Massachusetts, Dartmouth

Laurence Parker University of Illinois, UrbanaChampaign

Susan L. Robertson Bristol University

John Rogers University of California, Los Angeles

A. G. Rud Purdue University

Felicia C. Sanders The Pennsylvania State University

Janelle Scott University of California, Berkeley

Kimberly Scott Arizona State University

Dorothy Shipps Baruch College/CUNY

Maria Teresa Tatto Michigan State University

Larisa Warhol University of Connecticut

Cally Waite Social Science Research Council

John Weathers University of Colorado, Colorado Springs

Kevin Welner University of Colorado, Boulder

Ed Wiley University of Colorado, Boulder

Terrence G. Wiley Arizona State University

John Willinsky Stanford University

Kyo Yamashiro University of California, Los Angeles

* Members of the New Scholars Board 


\section{archivos analíticos de políticas educativas consejo editorial \\ Editor: Gustavo E. Fischman (Arizona State University)}

Editores. Asociados Alejandro Canales (UNAM) y Jesús Romero Morante (Universidad de Cantabria)

Armando Alcántara Santuario Instituto de Investigaciones sobre la Universidad y la Educación, UNAM México

Claudio Almonacid Universidad Metropolitana de Ciencias de la Educación, Chile

Pilar Arnaiz Sánchez Universidad de Murcia, España

Xavier Besalú Costa Universitat de Girona, España

Jose Joaquin Brunner Universidad Diego Portales, Chile

Damián Canales Sánchez Instituto Nacional para la Evaluación de la Educación, México

María Caridad García Universidad Católica del Norte, Chile

Raimundo Cuesta Fernández IES Fray Luis de León, España

Marco Antonio Delgado Fuentes Universidad Iberoamericana, México

Inés Dussel FLACSO, Argentina

Rafael Feito Alonso Universidad Complutense de Madrid, España

Pedro Flores Crespo Universidad Iberoamericana, México

Verónica García Martínez Universidad Juárez Autónoma de Tabasco, México

Francisco F. García Pérez Universidad de Sevilla, España

Edna Luna Serrano Universidad Autónoma de Baja California, México

Alma Maldonado Departamento de Investigaciones Educativas, Centro de Investigación y de Estudios Avanzados, México

Alejandro Márquez Jiménez Instituto de Investigaciones sobre la Universidad y la Educación, UNAM México

José Felipe Martínez Fernández University of California Los Angeles, USA
Fanni Muñoz Pontificia Universidad Católica de Perú

Imanol Ordorika Instituto de Investigaciones Economicas - UNAM, México

Maria Cristina Parra Sandoval Universidad de Zulia, Venezuela

Miguel A. Pereyra Universidad de Granada, España

Monica Pini Universidad Nacional de San Martín, Argentina

Paula Razquin UNESCO, Francia

Ignacio Rivas Flores Universidad de Málaga, España

Daniel Schugurensky Arizona State University

Orlando Pulido Chaves Universidad Pedagógica Nacional, Colombia

José Gregorio Rodríguez Universidad Nacional de Colombia

Miriam Rodríguez Vargas Universidad Autónoma de Tamaulipas, México

Mario Rueda Beltrán Instituto de Investigaciones sobre la Universidad y la Educación, UNAM México

José Luis San Fabián Maroto Universidad de Oviedo, España

Yengny Marisol Silva Laya Universidad Iberoamericana, México

Aida Terrón Bañuelos Universidad de Oviedo, España

Jurjo Torres Santomé Universidad de la Coruña, España

Antoni Verger Planells University of Amsterdam, Holanda

Mario Yapu Universidad Para la Investigación Estratégica, Bolivia 